\title{
Metastatic neck node- a clinical study of 60 cases
}

\author{
Maleka Afroz ${ }^{1}$, Nasima Akhtar ${ }^{2}$, Belayat Hossain Siddiquee ${ }^{3}$
}

\begin{abstract}
:
Metastatic neck node is not uncommon in the otolaryngology department of a tertiary level hospital. Ignorance, illiteracy, delay in seeking medical advice and poor orientation of our general practitioners regarding management causes these patients to suffer from marked morbidity and mortality. It is a prospective study with random selection of sixty (60) cases of metastatic neck node admitted in the otolaryngology department of BSMMU and Dhaka Medical College Hospital during a period extending from September, 2002 to August, 2003. Here 53(88.33\%) cases of metastatic neck nodes having a known primary in the head neck region and in other seven (11.67\%) cases primary site of malignancy could not be detected. The commonest site of known primary was supraglottic larynx. Highest number 19(31.67\%) of presentation was seen in $5^{\text {th }}$ decade. Male incidence 47(78.33\%) was more compared to female 13(21.67\%).
\end{abstract}

Keywords: Neck gland, Metastatic neck node, Unknown primary.

\section{Introduction}

A common denominator to all malignancy is their ability to metastasize. Why and how this phenomenon occurs has been the subject of much research and investigation. We do know however that metastasis is not a random event. ${ }^{1}$ Some tumour have the propensity for extensive local invasion without metastasis, whereas others metastasize early on their development. ${ }^{2}$ Cervical region is very rich in lymphatic supply; containing about 300 lymph nodes which may get involved in the clinical course of head and neck malignant disease. ${ }^{3}$

The mere presence of carcinoma in a cervical node is said to reduce for a given lesion the number of patients who will survive for 5 years by approximately $50 \%$. The number of survival has been noted to reduce further when multiple nodes are involved or extranodal spread of the disease occurs. ${ }^{4}$ With further progression the incidence of distant metastasis, which has always been viewed as being uncommon also increases dramatically making the disease incurable. ${ }^{5}$ So, early treatment of the primary tumour and metastatic lymph nodes is essential for good locoregional control, reduction of incidence of distant metastasis and improved survival. Historically in $50-67 \%$ cases of

1. Assistant Professor, Department of ENT \& HeadNeck Surgery, BBMH, USTC, Foy's lake, Chitttagong.

2. Assistant Professor, Department of ENT \& HeadNeck Surgery, BSMMU, Shahbag, Dhaka.

3. Associate Professor, Department of ENT \& HeadNeck Surgery, BSMMU, Shahbag, Dhaka.

Address correspondence to : Dr. Maleka Afroz, Assistant Professor, Department of ENT \& Head-Neck Surgery, BBMH, USTC, Foy's lake, Chittagong. metastatic neck node primary site can be identified by taking comprehensive history and initial physical examination. However, further evaluation by imaging, endoscopy and biopsy may be required for confirmative diagnosis and effective management. ${ }^{6,7,8}$ This study is expected to show different types of head and neck cancers metastasizing to cervical lymph nodes, the age and sex distribution and clinical presentation of metastatic neck node. FNAC and biopsy of the neck node was taken as primary selection criteria. Data collected from this study have been tabulated, analyzed and compared with some published reports from both home and abroad.

\section{Objectives}

Since metastatic neck node is regarded as an important prognostic factor in head neck malignancy we should have a proper broad based study with it in our country. The objectives of this study was-

1. To evaluate different primary sites in head and neck region metastasizing to cervical lymph nodes.

2. To evaluate the age and sex distribution.

3. To find out the usual mode of presentation of metastatic neck disease.

\section{Methods}

It was a prospective study carried out in the in-patient department of ENT and Head-Neck Surgery of Bangabandhu Sheikh Mujib Medical University and Dhaka Medical College Hospital from September, 2002 to August, 2003. Altogether 60 randomly selected cases of metastatic neck node consisting of different 
age and sex group had been studied. FNAC biopsy was done as the primary selection criteria. Metastatic neck node irrespective of its primary origin known or unknown, were included in the study.

After taking a comprehensive history every patient was subjected to a thorough physical examination with particular emphasis to head neck region. Neck was examined very carefully for the side, size, number and level of lymph node involvement, their consistency and mobility. All cases were advised for FNAC of enlarged neck node. The cases revealed metastatic deposit in the cytology test were included into the series.

Besides FNAC, radiological and endoscopic examinations were carried out as and when necessary. Tissue was sent from the suspected sites of primary for histopathological examination in every case. Those with negative histopathological report and having no clinical symptoms and signs suggestive of primary pathology in head neck region or no evidence of any primary lesion even after intensive investigations of chest and abdomen were taken as occult primary.

\section{Result}

Altogether 60 cases of metastatic neck node had been studied in the present series.

The results are shown in following tables.

Table- I

Incidence of known primary and unknown primary $(n=60)$

\begin{tabular}{lcc}
\hline $\begin{array}{l}\text { Type of primary } \\
\text { tumour }\end{array}$ & $\begin{array}{c}\text { Number of } \\
\text { patients }\end{array}$ & $\begin{array}{c}\text { Percentage } \\
(\%)\end{array}$ \\
\hline Known primary & 53 & 88.33 \\
Unknown primary & 07 & 11.67 \\
\hline
\end{tabular}

Table - II

Histological diagnosis of Known primary tumour $(n=53)$

\begin{tabular}{lcc}
\hline Type & $\begin{array}{c}\text { Number of } \\
\text { cases }\end{array}$ & $\begin{array}{c}\text { Percentage } \\
(\%)\end{array}$ \\
\hline Squamous origin & 43 & 81.13 \\
Non squamous origin & 10 & 18.87 \\
\hline
\end{tabular}

Table III

Distribution of known primary sites $(n=53)$

\begin{tabular}{lcc}
\hline Primary sites & $\begin{array}{c}\text { No of } \\
\text { cases }\end{array}$ & $\begin{array}{c}\text { Percentage } \\
(\%)\end{array}$ \\
\hline Larynx & 22 & 36.66 \\
Pyriform fossa & 09 & 15.00 \\
Nasopharynx & 04 & 06.67 \\
Base of the tongue & 03 & 05.00 \\
Buccal mucosa & 02 & 03.33 \\
Oral tongue & 01 & 01.67 \\
Nose & 01 & 01.67 \\
Tonsil & 01 & 01.67 \\
Thyroid gland & 08 & 13.33 \\
Parotid gland & 02 & 03.33 \\
\hline
\end{tabular}

Table IV

Age incidence of metastatic neck node $(N=60)$

\begin{tabular}{lcc}
\hline $\begin{array}{l}\text { Age group } \\
\text { (years) }\end{array}$ & $\begin{array}{c}\text { No of } \\
\text { cases }\end{array}$ & $\begin{array}{c}\text { Percentage } \\
(\%)\end{array}$ \\
\hline $20-30$ & 05 & 08.33 \\
$31-40$ & 08 & 13.33 \\
$41-50$ & 04 & 06.67 \\
$51-60$ & 03 & 05.00 \\
$61-70$ & 02 & 03.33 \\
$71-80$ & 01 & 01.67 \\
$81-90$ & 01 & 01.67 \\
$91-100$ & 01 & 01.67 \\
\hline
\end{tabular}

Table V

Sex incidence of metastatic neck node $(N=60)$

\begin{tabular}{lcc}
\hline $\begin{array}{l}\text { Name of the } \\
\text { sex }\end{array}$ & $\begin{array}{c}\text { No of } \\
\text { cases }\end{array}$ & $\begin{array}{c}\text { Percentage } \\
(\%)\end{array}$ \\
\hline Male & 47 & 78.33 \\
Female & 13 & 21.67 \\
\hline
\end{tabular}


Table- VI

Distribution and status of involved lymph nodes ( $n-60)$

\begin{tabular}{lll}
\hline & & $\begin{array}{l}\text { No. of cases with } \\
\text { Percentage (\%) }\end{array}$ \\
\hline $\begin{array}{lll}\text { Distribution } \\
\text { of nodes }\end{array}$ & Unilateral & $49(81.67)$ \\
& Bilateral & $10(16.67)$ \\
& Contralateral & $01(01.66)$ \\
No. of node & Single & $22(36.67)$ \\
involvement & Multiple & $38(63.33)$ \\
& & \\
Consistency & Hard & $32(53.33)$ \\
& Firm to hard & $24(40.00)$ \\
& Firm & $03(05.00)$ \\
& Soft & $01(01.67)$ \\
Mobility & Mobile & $36(60.00)$ \\
& Fixed & $24(40.00)$ \\
Size of lymph & $<3 \mathrm{~cm}$ & $16(26.67)$ \\
nodes & $3-6 \mathrm{~cm}$ & $20(33.33)$ \\
& $>6 \mathrm{~cm}$ & $24(40.00)$ \\
\hline
\end{tabular}

Table VII

Level of lymph nodes ( $N=60$ )

\begin{tabular}{lcc}
\hline $\begin{array}{l}\text { Level of lymph } \\
\text { nodes }\end{array}$ & $\begin{array}{c}\text { No of } \\
\text { cases }\end{array}$ & $\begin{array}{c}\text { Percentage } \\
(\%)\end{array}$ \\
\hline Level - I & 03 & 05.00 \\
Level - II & 24 & 40.00 \\
Level - I+II & 03 & 05.00 \\
Level - III & 02 & 03.33 \\
Level - II+III & 18 & 30.00 \\
Level - II+III+IV & 05 & 08.33 \\
Level - IV & 01 & 01.66 \\
Level - II+IV & 01 & 01.67 \\
Level - II+III+IV+V & 02 & 03.33 \\
Level - IV+V & 01 & 01.67 \\
\hline
\end{tabular}

Highest lymph node level involved is level II \& III.
Discussion :

Metastatic neck node is not a very rare clinical entity in otolaryngological practice in a tertiary level hospital. However it is difficult to give an exact data of its incidence in our country. Most of the studies were carried out with cervical lymphadenopathy where metastatic neck node was described as one of the cause of enlargement of cervical lymph node in adults.

More then half of the total body nodes are distributed in the neck draining the head neck region studded with dense capillary network of lymphatics. So the rate at which malignancy spreads from this region to the neck is very high.

FNAC of neck swelling showing metastatic deposit of squamous or non-squamous origin was taken as primary selection criteria. Leveling of lymph node group was done in accordance with Memorial Sloan Kettering Hospital (1981). Staging of lymph node group was done after AJC and UICC (1987).

Altogether 60 cases of metastatic neck node had been studied in the present series. A primary lesion could be identified in $53(88.53 \%)$ cases while it remains undetected in $7(11.7 \%)$ cases. Two studies carried out abroad showed rate of incidence similar to our study. One study in Liverpool, England demonstrated known primary in $89.3 \%$ and unknown primary in $10.3 \%$ cases and another study in USA showed known sites of origin of metastatic neck node in $90 \%$ cases and unknown primary in $10 \%$ cases. $^{9,10}$

Among the primary sites $43(81.13 \%)$ cases were seen to arise from squamous lining of upper aero-digestive tract and $10(18.87 \%)$ cases were having a nonsquamous origin arising from thyroid gland $8(15.09 \%)$ and parotid gland $2(3.78 \%)$. The study reveals that metastasis from thyroid gland malignancy is not a very uncommon entity.

Among the known primary sites highest incidence of metastasis was seen from supraglottic larynx $22(36.66 \%)$ with involvement of medial wall of the pyriform fossa or extension into it in $40 \%$ cases. Metastasis from pyriform fossa was seen in 09(15\%) cases, from nasopharynx in 04(6.67\%) cases, from base of the tongue in $03(5 \%)$ cases, from buccal mucosa in $02(3.33 \%)$ cases, from oral tongue in $01(1.67 \%)$ case, from tonsil in $01(1.67 \%)$ case and from nose in $01(1.67 \%)$ case. The studies about primary sites of metastatic neck node at home and abroad however demonstrate a diverse picture. In a study with metastatic 
neck node in the department of otolaryngology, Mount Sinae Hospital and Sunnybrook Medical Centre, Toronto; $40 \%$ cases of primary tumour was seen in tongue, $20 \%$ cases in larynx, $20 \%$ cases in the floor of the mouth, $7 \%$ cases in tonsil, $3 \%$ cases in the palate and $10 \%$ cases in other miscellaneous sites. The reason it did not match to other studies alike as been mentioned by them is absence of selectivity for primary sites. ${ }^{11}$ Another study in Khartum Teaching Hospital, Sudan commonest primary site of malignancy was nasopharynx. ${ }^{12}$ It might be due to their social habit and /or genetic predisposition.

Enlargement of lymph nodes in neck was the principal complaint in all 60(100\%) cases. Besides it 26(43.33\%) patients presented with dysphagia, 23(38.33\%) cases presented with hoarseness of voice, $8(13.33 \%)$ patients with respiratory distress, 5(8.33\%) patients with stridor, $5(8.33 \%)$ patients with referred otalgia, $5(8.33 \%)$ patients with pain in throat, $4(6.67 \%)$ patients with nasal obstruction, 3(5\%) patients with epistaxis, 3(5\%) patients with severe headache, 3(5\%) patients with dysarthria, 1(1.67\%) patient with trismus, $1(1.67 \%)$ patient with discharging fistula in neck, $7(11.7 \%)$ patients with cranial nerve palsy and $7(11.67 \%)$ patients with anorexia and weight loss. $8(13.33 \%)$ cases presented with thyroid swelling and 2(3.33\%) cases with parotid gland swelling.

The disease was unilateral in $49(81.67 \%)$ cases, bilateral in $10(16.67 \%)$ cases and contra-lateral in $1(1.66 \%)$ case. A work on metastatic neck disease done by G.B. Snow and his team in Netherland Cancer Institute, Amsterdam; ipsilateral enlargement of lymph nodes was demonstrated in $87 \%$, bilateral in $8.6 \%$, and contralateral in $3.6 \%$ cases. $^{13}$

Lymph node involved was single in 22(36.66\%) patients and multiple in $38(63.33 \%)$ cases. G.B. Snow and his team of Netherland Cancer Institute, Amsterdum; got $61.3 \%$ cases of single node enlargement and $38.7 \%$ cases of multiple lymph nodes enlargement in their series representing their early presentation.

In this study nodes were found less than $3 \mathrm{~cm}$ in size in $16(26.67 \%)$ cases, 3 to $6 \mathrm{~cm}$ in 20(33.33\%) cases and more than $6 \mathrm{~cm}$ in 24(40\%) cases. But study carried out by G.B. Snow and his team showed enlarged lymph node less than $3 \mathrm{~cm}$ in size in $85 \%$ and more than $3 \mathrm{~cm}$ in only $15 \%$ cases. ${ }^{13}$ This indicates late presentations of the patients of our country which reflects their educational and socioeconomic status fairly well.
Lymph nodes were hard in consistency in 32(53.33\%) cases, firm to hard $24(40 \%)$ cases, firm $03(5 \%)$ cases and soft in $1(1.67 \%)$ case.

In $36(60 \%)$ cases lymph nodes were found mobile and $24(40 \%)$ cases they were fixed. In the studies abroad fixity of nodes varied from $16.4 \%$ to $29.6 \%$ representing their early presentation once again. ${ }^{9,13}$

While leveling of the lymph nodes was concerned most commonly involved lymph node region was found to be level II (40\%) followed by level II + III (30\%). This is found in agreement with most of the other studies carried out at home and abroad. ${ }^{11,14}$

$20(33.33 \%)$ cases fell in stage $\mathrm{N} 1,8(13.34 \%)$ in stage $\mathrm{N} 2 \mathrm{~A}, 11(18.33 \%)$ in stage N2B, $5(8.4 \%)$ in N2C and $16(26.66 \%)$ patients in stage N3. The results of this part of the study could not be compared due to lack of studies following the staging of lymph node group after AJC and UICC.

\section{References}

1. Fidler I.J. The Biology of cancer metastasis and implication for therapy. Current Prob. Surgery, 1987; 24:137-190.

2. Loren W. Savoury, Jack L. Gluckman. Cervical metastasis, Otolaryngology $3^{\text {rd }}$ edition, vol.3 , W.B. Saunder's Company, 44: 2565-2577.

3. Al- Fallouji MAR. Cervical lymph nodes, postgraduate surgery- The candidates guides, $2^{\text {nd }}$ edition, Oxford : Butterworth - Heinemann, 1998; 376-378.

4. Goepfert H. Biology of Head and Neck Cancer, Cancer Bull., 1987; 39(2): 73-79.

5. Frederick Mc. Guirt Sr. Differential Diagnosis of Neck masses, Otolaryngology Head and Neck Surgery, $3^{\text {rd }}$ edition, vol.3, 88: 1686-1697.

6. Jesse R.H., Perez C.A., Fletecher G.H. Cervical Lymph node metastasis, Unknown primary causes, Cancer 31:854.

7. Jones A.S. and others, Squamous carcinoma presenting as an enlarged cervical node, Cancer 71: 1756.

8. Martin H., Romieu C. Cervical lymph node metastasis as the first symptom of cancer, Surg. Gynecol Obstet 78:133. 
9. Stell P. M. Dalby, J.E. Singh S.D., Taylor W. The fixed cervical lymph node, Cancer, 1984; 53 : 336-341.

10. David E. Schuller, Charles E. Platz, Charles J. Krause. Spinal accessory lymph nodes - A prospective study of metastatic involvement, Laryngoscope,1978; 88:439-450.

11. David E. Schuller, W. Fred. Mc Guirt and others. The prognostic significance of metastatic cervical lymph nodes, Laryngoscope, vol XC, no-4 : 557570.
12. Kheiry J.Ahmed M.E. Cervical lymphadenopathy in Khartum, Areport of 92 cases, Khartum Teaching Hospital, Sudan, 1992.

13. Snow G.B., Annyas A. Prognostic factors of neck node metastasis, Clin. Otolaryngol, 1982; 7: 185-191.

14. Lindberg R. D. Distribution of cervical lymph node metastasis from squamous cell carcinoma of upper respiratory and digestive tract, Cancer, 29:1446-1449. 